\title{
Research and Assumption on the Practice Teaching System of "Electronic Technology Foundation"
}

\author{
Renbo $\mathrm{Xu}^{1,2, a}$, Youhui Zou ${ }^{1, \mathrm{~b}}$, and Fenglian Yuan ${ }^{1, \mathrm{c}}$ \\ ${ }^{1}$ School of artificial intelligence, Nanchang Institute of Science and Technology Nanchang, 330108, China \\ ${ }^{2}$ Physics and Microelectronics Institute, Central South University Changsha, 410083, China \\ aCorresponding author: 1310079831@qq.com, bYouhui@163.com, FengLian Yuan@163.com
}

Keywords: practical teaching system; practical teaching platform; engineering practice ability; research and assumption

\begin{abstract}
According to the existing problems in the practice teaching of "electronic technology foundation", a practical teaching system based on comprehensive training of students' engineering practice ability is constructed. The practical teaching system organically integrates the practical teaching and extracurricular practice teaching in class, and supports each other. The practical teaching in the course embodies the teaching concept of "basic, comprehensive and advanced", and adopts the hierarchical training scheme to meet the requirements of different teaching objects. At the same time, it further optimizes the practical teaching content and improves the practical teaching method. The extracurricular practice adopts "multi-level, open and comprehensive" teaching mode by relying on science and technology innovation and discipline competition, maximizing the innovation potential of students.
\end{abstract}

\section{Introduction}

"Electronic technology foundation" course is a very important specialized technical basic course for engineering electronic information, electrical and other majors. This course is divided into two parts: theoretical teaching and practical teaching, while practical teaching is an important link to cultivate students' ability of practice, engineering consciousness, cooperation spirit and innovation ability. The problems of current electronic technology practice teaching are that the research on the electronic technology practice teaching system is not deep, electronic technology practice teaching is not enough for students; electronic technology practice teaching content is old; the practical teaching of electronic technology is not practical, and the training of students' innovation ability and engineering practice ability needs to be improved. For this purpose, this paper aims at the needs of undergraduate practical teaching and innovative teaching and constructs a practical teaching system which focuses on cultivating students' comprehensive application ability, engineering practice ability and system design ability.

\section{Construct a new practical teaching system based on the practical teaching platform}

The practical teaching platform supported by electronic technology course is "Electronic technology experiment platform (the platform includes" analogue electronic technology foundation experiment and digital electronic technology foundation "), "EDA (electronic design automatic) technology experiment platform", "course design of electronic technology experiment platform" and "electronic design innovation experiment platform". According to the experimental environment and practical teaching characteristics of each practical teaching platform, a practical teaching system of "three-dimensional, hierarchical, modular, comprehensive and open" can be constructed. The system will be divided into two parts: classroom practice teaching practice teaching and extracurricular practice teaching. The practical teaching in the course emphasizes "basic, comprehensive and engineering" while the extracurricular practice teaching emphasizes "exploratory, research-oriented and innovative". "Practical teaching in class" and "extracurricular 
practice teaching" achieve coordinated development and complementary advantages. In addition, the teaching modules can be divided into different teaching modules, and each teaching module can be combined to meet the requirements of students from different majors and levels.

\section{The teaching concept of "basic, comprehensive and advanced"}

\subsection{The basic practical teaching module implements the "hierarchical, gradient" teaching}

The basic practice teaching adopts the mode of "gradation and gradient", which conforms to the training law of ability and quality, and is convenient for the whole optimization experiment teaching content. The basic practice teaching is divided into three levels: (1) Basic level experiment. This level is primarily a confirmatory experiment. Basic contents include the use of common electronic instruments and components, the performance test of integrated circuits, and the measurement of classical electronic circuits. The aim is to deepen students' understanding of the basic theory of electronic technology and to train students' interest in electronic technology experiment. (2) Unit circuit design experiment. This level mainly cultivates students' ability to experiment and design independently. The teacher generally gives the structure of the circuit, puts forward the performance index of the circuit to realize, lets the classmate choose the electronic component independently, completes the installation, the debugging and the circuit analysis independently. As shown in figure 1, the circuit adopts a Link Switch-TN device to provide the constant current of $130 \mathrm{~mA}$ and the output voltage is 70V DC. Diode D1 D4 provides full wave rectification while high voltage capacitor C2 maintains a stable DC bus voltage. In the U1 guide band, the current flows through the capacitance C4, the load (70VLED string) and inductance L2. This current causes L2 to store a certain amount of energy and provide it to the load.

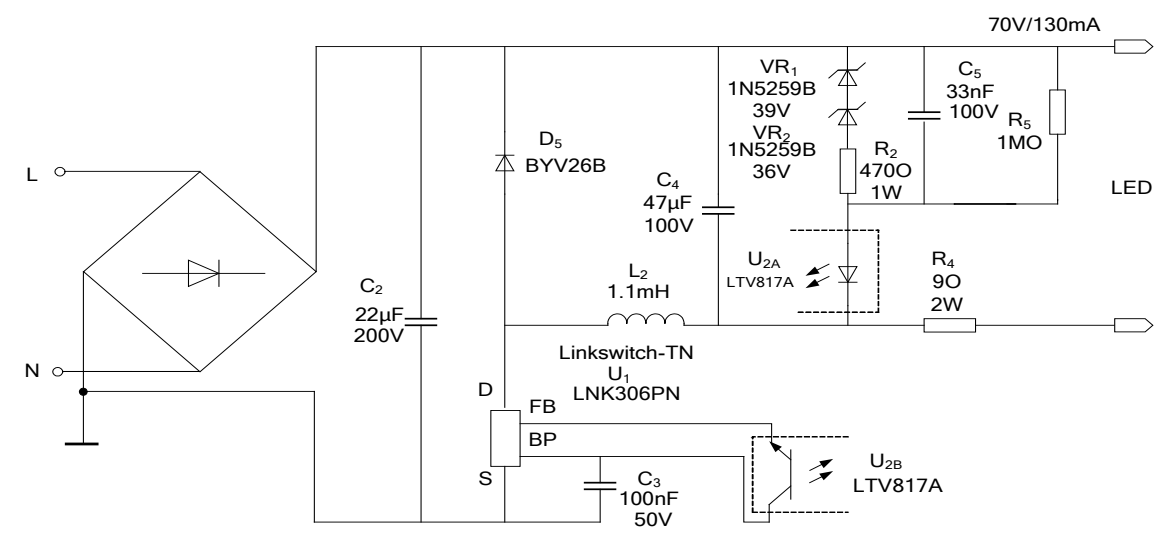

Figure 1 Semiconductor Lighting Driven Design Based on Link Switch-TN Device

\subsection{EDA practical teaching module implements "advanced and modern" teaching}

At present, EDA (electronic design automation) technology has become the most important means of electronic system design. It will play an important role in training students' electronic design ability and innovation ability. To strengthen EDA experimental teaching, its implementation plan is: (1)The teaching environment of EDA experimental software is established and the classic EDA tool softwares such as Multisim, Protel, Quartus II and ISE are installed. (2) The "FPGA modern digital system design device" is developed. The experimental device adopts the digital system developed by Xilinx company's latest technology Spartan-6 FPGA, which can complete the design of various digital systems on the system. (3) The traditional experiment is synchronized with EDA experiment. The EDA tool is characterized by software simulation and simulation hardware circuit. Only by combining the software and the hardware circuit can the function of EDA experiment teaching be fully utilized, so that the theory and practice can be combined organically. As shown in figure 2, in the case of rectification and initial ac input signal, the change between voltage and current of the control system is zero phase. It can be concluded that the system has good stability and harmonic disturbance. 


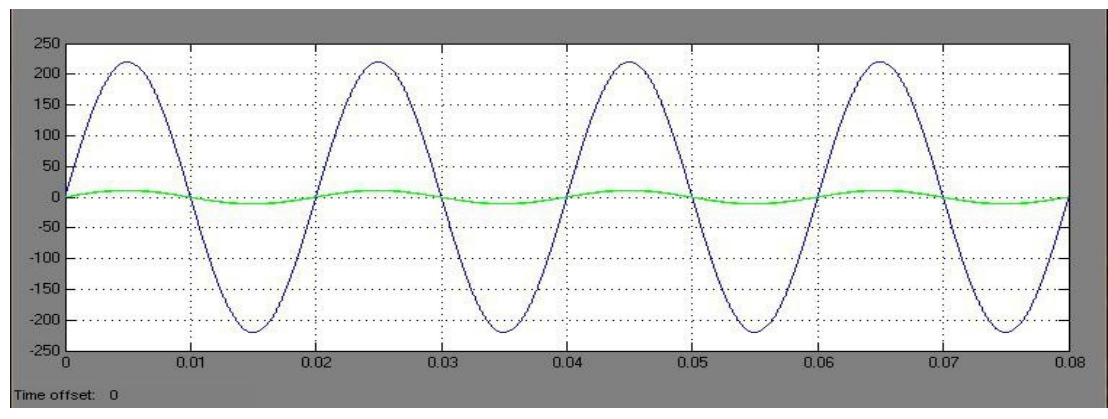

Figure 2 Control System Voltage and Current Waveform Diagram

\section{Extracurricular practice teaching mode}

It advocates the teaching mode of "Learning in practice" and cultivates students' team spirit. During the summer course of "electronic design competition training", after years of practice and exploration, this paper puts forward the independent learning mode of "elaboration and practice, laboratory opening and strengthening engineering project training", which actively mobilizes students' creative potential and receives good results. We can keep the lab open all day. We can open the laboratory, laboratory equipment, laboratory equipment and library materials around the clock to students, and provide students with a relaxed and effective learning environment. In the study, we should pay attention to the role of key players and form a learning atmosphere of "competing, learning, driving, helping and exceeding". At the same time, we should pay attention to the communication between students, forming an atmosphere of "fighting hard, striving for the upstream, helping each other and working together".

\section{Conclusions}

The practical teaching reform of "electronic technology foundation" has been implemented and perfected in the college students majoring in electrical, automation and measurement and control for many years, which has achieved remarkable teaching effect. It has enlarged the benefit group, enhanced the student's interest in learning, and improved the student's engineering application ability. Each year a large number of students actively apply for various scientific and technological innovation projects, and many have received funding from "the national college innovation training program project". It has solved the contradiction between "the content is more and less" in the practical teaching of "electronic technology foundation", and solved the problems such as how to divide the practical work properly, to connect and support each other.

\section{Acknowledgements}

This research was financially supported by Key scientific research projects of Jiangxi Provincial Department of Education (Grant NO. GJJ161218,). Scientific research start-up funding (Grant NO. NGRCZX-17-01).

\section{References}

[1] Yao Yingying, Wei Wei. Exploration of relevance teaching mode of electric basic experimental class [J]. Journal of Electrical and Electronic Teaching, 2013,35 (3) :69-71.

[2] Qian Xiaoming. Exploration and practice of open management mechanism of university laboratory [J]. Experimental Technology and Management, 2013,30 (11) :40-43.

[3] Xiao Kan, Yishi, Yan Guoping. Exploration and practice of innovative electric-electronic all-open experimental teaching mode [J]. Laboratory Research and Exploration, 2015,29 (4) :79-82.

[4] Wang Gesi, Zhao Yanfeng. Research and practice of the experimental curriculum system of 
analog electronic technology [J] Experimental Science and Technology, 2014, 10(5) :99-102.

[5] Xing Xiaorui. The exploration and practice of the teaching of "simulated electronic technology experiment" [J] Journal of Electrical and Electronic Teaching, 2013, 35(1) :86-87.

[6] Li Zhijun, Chen Wanpei. The experimental teaching reform of the simulation circuit [J] Experimental Science and Technology, 2015, 11(4) :78-80.

[7] Xie Dong, Guan Zhengqiang. Design and exploration of comprehensive experimental project of electronic technology curriculum [J] Experimental Science and Technology, 2015,11 (4) :101-104.

[8] Han Shunjie, Jiang Changhong. Research and practice of open operation management mode of college students' innovation base [J] Experimental Technology and Management, 2013,30 (6) :119-121.

[9] Yang Yi, Xu Peng. Electronic design competition and practical teaching reform [J] Laboratory Research and Exploration, 2014, 32(4) :172-175. 